\title{
El malogrado proyecto del ferrocarril peninsular del Distrito Norte de la Baja California, 1887-1892
}

Hilarie J. Heath*

\begin{abstract}
Resumen
Entre julio de 1891 y mayo de 1892, la Mexican Land and Colonization Company, empresa británica que tenía en concesión la mayor parte del territorio baldío del norte de la península de Baja California, construyó 27 kilómetros de vía férrea con el objetivo de abrir terrenos a la colonización. Pero el tren, conocido como el Ferrocarril Peninsular, partía de San Quintín, una bahía de poco calado y prácticamente inservible como puerto naviero, y no llegó a ningún lado. Sin embargo, el objetivo de este trabajo no es analizar las razones por las cuales el proyecto ferroviario no llegó a su feliz término, sino que se enfoca en las controversias y conspiraciones que se dieron a raíz de la pugna entre Estados Unidos y Gran Bretaña por la hegemonía en el noroeste de México.
\end{abstract}

Palabras clave: ferrocarril, Baja California.

\begin{abstract}
Between July of 1891 and May 1892, the Mexican Land and Colonization Company, a British enterprise with a concession over the major part of Baja California's wastelands, laid 27 kilometers of rail of what was to be known as the Peninsular Railway with the expectation of opening up lands to cultivation and settlement, and attracting investment. But the train's starting point was San Quintin, a shallow bay illsuited to becoming an important shipping port and, as far as the tracks had been built, led to nowhere. However, the objective of this paper is not to analyze the reasons for which the railway project did not come to a happy termination. Rather, it focuses on the controversies and conspiracies which surrounded its construction, arising from the struggle between the United States and Great Britain for predominance in Mexico’s far northwest.
\end{abstract}

Keywords: railway, Baja California.

* Profesora-investigadora de la Facultad de Ciencias Administrativas y Sociales de la Universidad Autónoma de Baja California. Unidad Universitaria Valle Dorado. Correo electrónico: hheath@uabc.edu.mx 


\section{Introducción}

Uno de los puntos cardinales dentro del propósito modernizador del porfiriato fue dotar al país de vías ferroviarias para lograr una "efectiva integración nacional” (Riguzzi, 1996:214) tanto económica como social y política. Pero así como se establecía como una prioridad dentro del proyecto de nación, difícilmente se llegaba a un consenso en cuanto a las estrategias a seguir, los subsidios a otorgar, la procedencia más adecuada del financiamiento, las rutas preferentes y -cuestión primordial a resolver- la prudencia del enlazamiento con el sistema ferroviario del vecino del norte. Sin embargo, aún dentro de los incesantes debates y controversias que se entablaban a cada momento, sí se logró desarrollar un sistema ferroviario que consiguiera integrar a una buena parte del país.

La historia del sistema ferroviario, de por sí compleja, se enreda todavía más con los desatinos. Frente a los logros y aciertos, hubo un sinfín de concesiones y proyectos, rodeados de intrigas, manipulaciones, fraudes y traspasos, unos de buena fe que no consiguieron reunir el capital requerido, otros no tanto; algunos que sí lograron tender unos kilómetros de vías, otros que "no rebasaron el campo de las intenciones" (Ortiz, 1987:126). Entre estas historias de fracasos se encuentra la del Ferrocarril Peninsular que, de haberse llevado a cabo, hubiera significado más de mil kilómetros de vías desde la frontera internacional entre California, Estados Unidos, y Baja California hasta la bahía de Los Ángeles en la costa del Golfo.

La construcción de una vía de ferrocarril pareciera ser un paso lógico para una compañía colonizadora que adquiría el compromiso de poblar una región tan vasta y tan desprovista de cualquier tipo de comunicación como lo era todavía el norte de la península bajacaliforniana a finales del siglo xix. En 1887 se firmó un contrato entre el gobierno mexicano y la Compañía Internacional, una empresa de deslinde y colonización de capital estadounidense, para la construcción de un ferrocarril en la península de Baja California. Entre 1891 y 1892, cuando la empresa había pasado a manos inglesas, se construyeron 27 kilómetros de vía a partir de la bahía de San Quintín en la costa del Pacífico. A pesar de tener la aprobación para seguir con la construcción del siguiente tramo, la obra efectiva terminó allí. En 1904 pasó a ser propiedad de la nación y el gobierno mexicano se dedicó a la tarea de buscar el mejor postor para el levantamiento de la 
vía y la venta tanto del material utilizado en la construcción como del material rodante: una locomotora y diez vagones traídos de Inglaterra.

Cabe preguntar qué interés pudiera tener, fuera de los confines de la historia microrregional que entusiasma a unos pocos aficionados nativos, un tramo de ferrocarril que nunca llegó ni siquiera a ser funcional: la bahía de San Quintín tenía poco calado, escasamente llegaban barcos, su población era muy reducida y a la vía le faltaron unos 5 o 6 kilómetros para llegar al rancho más cercano. Sin embargo, la polémica que se suscitó en torno a su construcción, la lucha por el control comercial regional y las intrigas por socavar las actividades de una empresa británica en la región fronteriza con Estados Unidos, son temas en sí altamente sugestivos que trascienden ámbitos locales y subrayan el enorme reto para emprender un proyecto de colonización y desarrollo, a la vez que muestran la vulnerabilidad del extremo noroeste a finales del siglo xix.

El tema del inexistente ferrocarril peninsular ya ha sido objeto de estudio en la publicación post-mortem del periodista Richard Dodge, "Low Rails in Lower California”, aparecida en 1964 sin fuentes citadas, y el capítulo de John A. Kirchner, "The Peninsular Railroad of Baja California. San Quintin to Oblivion”, en su libro Baja California Railways, publicado en 1988. Aunque este último es un detallado trabajo de investigación centrado en el ferrocarril, incurre en varias inexactitudes sobre la compañía colonizadora y sus actividades en la península. Más reciente pero menos conocida, la tesis de maestría de James Yaeger (1994), "Mexican Land and Colonization Company, 1889-1917. British Venture Beyond the Pale", como lo indica su título, se enfoca en el desempeño de la empresa colonizadora, lo que permite una visión mejor integrada y más amplia de la relación de sucesos en torno al fracasado proyecto ferroviario. ${ }^{1}$

Uno podría decir que el tema ha sido ampliamente cubierto, aunque es de notar que dentro de la historiografía nacional no se llega ni siquiera a mencionar (con demasiada frecuencia, el noroeste mexicano efectivo termina con Sonora y Chihuahua). Sin embargo, se consideró pertinente retomarlo por varias razones. En primer lugar, ninguno de los autores

\footnotetext{
${ }^{1}$ Kearney (1944:102-107) también toca el tema del ferrocarril de paso, así como las intrigas en relación al proyecto, investigación pionera cuyas fuentes se limitan en gran parte a los periódicos de la época.
} 
mencionados tenía a su disposición una serie de documentos de la Secretaría de Comunicaciones y Obras Públicas (scop) que, entre otras cosas, proporciona la perspectiva oficial de lo que sucedía en la región norte de la península a finales del siglo decimonónico; en segundo, porque a la hora de examinar nuevas fuentes, así como revisar documentos viejos y conocidos, es inevitable incurrir en discrepancias con los autores citados. Por último, el tema no deja de tener cierta vigencia, ya que no cesa de plantearse la posibilidad de un ferrocarril entre algún punto de la península y la frontera, resucitándose algunos de los viejos argumentos esbozados más de cien años atrás.

\section{La Compañía Internacional y la concesión ferroviaria}

En 1884 se firmó un contrato de colonización entre el gobierno mexicano y Luis Hüller, alemán naturalizado mexicano, con el que recibía en concesión todos los terrenos baldíos entre $29^{\circ}$ y $32^{\circ} 42^{\prime}$ latitud norte de la península bajacaliforniana. Hüller se había asociado con George Sisson, estadounidense, en el entendimiento de que éste proporcionaría el capital necesario. Pero ante la magnitud del compromiso, ${ }^{2}$ buscaron un grupo de financieros en Estados Unidos que organizó la International Company of Mexico (Compañía Internacional de México) con sede en Hartford, Connecticut, y adquirió los derechos a todas las concesiones de Hüller y Sisson. Las obligaciones contraídas, en lo que atañe a Baja California, abarcaban el deslinde y la colonización del extenso terreno del norte de la península.

Tres años después, en mayo de 1887, se formalizó otro acuerdo entre Hüller, como representante de la compañía, y el gobierno mexicano para una concesión ferroviaria: el derecho de construir el ferrocarril de Baja California y de operarlo durante un periodo de 99 años. En este momento inicial, se autorizaba la construcción de cuatro rutas, todavía vagamente definidas: 1) de Tijuana a la bahía de los Ángeles, pasando por la bahía de

${ }^{2}$ Además de la concesión en Baja California, Hüller consiguió otras nueve concesiones en los estados de Sonora, Chihuahua, Chiapas y Guerrero; y aparte del terreno directamente concesionado en la península, Hüller/Sisson compraron a Adolphe Bulle y a Telésforo García los derechos de sus concesiones (Holden, 1990:585). 
Ensenada de Todos Santos, el valle de La Trinidad y San Quintín; 2) de Tijuana a Puerto Isabel, con ramal al punto en que la línea divisoria corta el Río Colorado; 3) de Puerto Isabel a Magdalena, para entroncar con el ferrocarril de Sonora, pasando por Altar; 4) de Magdalena a Paso del Norte, para entroncar con el Ferrocarril Central (Lower Californian, 1887, 18 agosto). ${ }^{3}$ (ver figura 1 ).

Figura 1

Las rutas proyectadas del Ferrocarril Peninsular, 1887 y 1890

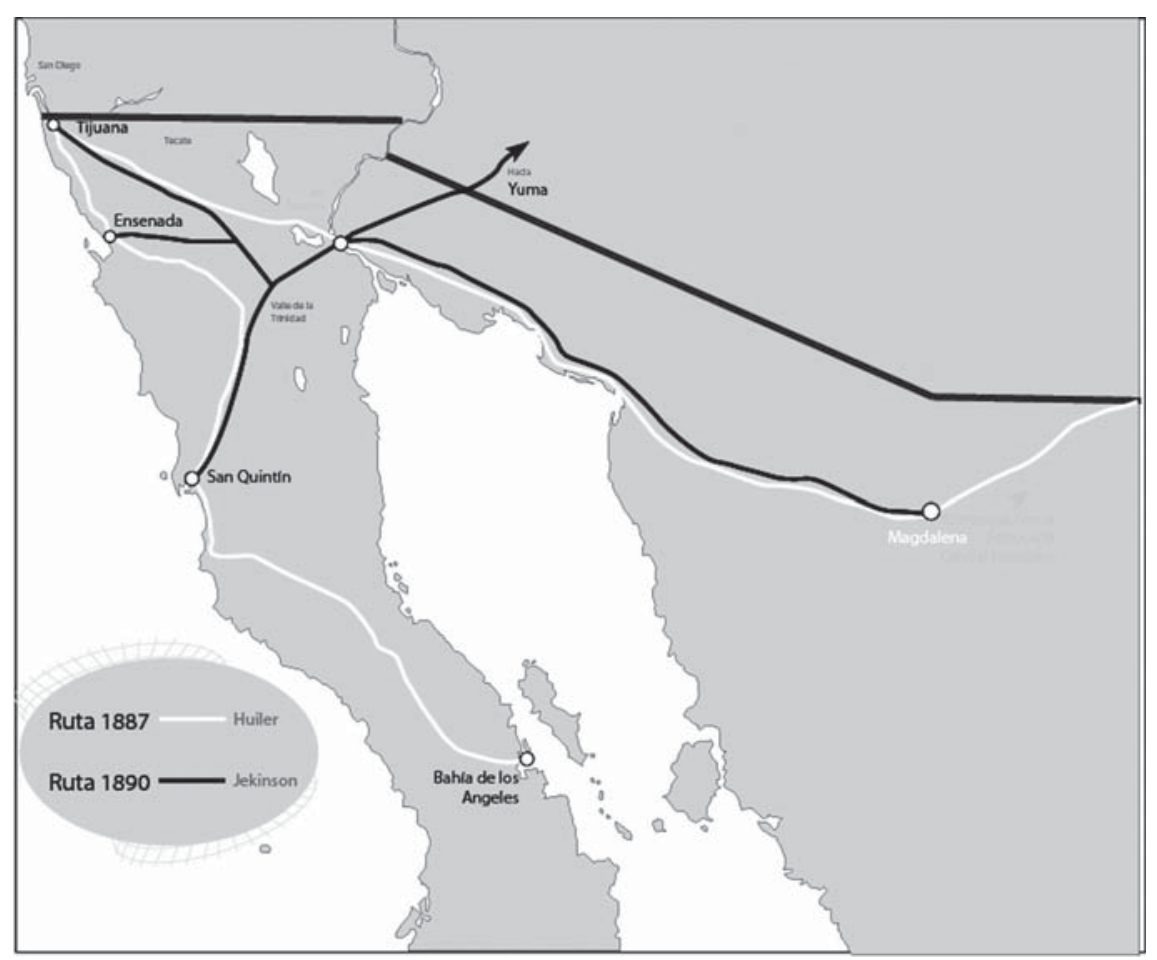

Fuente: Elaborado por Manuel A. Sánchez Fernández con información proporcionada por la autora.

\footnotetext{
${ }^{3}$ La concesión se firmó el 25 de mayo de 1887. Según Dodge (1964), al obtener la concesión, la Compañía Internacional de inmediato organizó la San Diego and International Railway Company, pero no cita fuentes y no se ha encontrado ninguna otra referencia a la posible existencia de esta empresa.
} 
Había un plazo de un año para empezar los trabajos de construcción; en dos años había que concluir los primeros 20 kilómetros de vía; en 12 años se comprometía la empresa a terminar las primeras dos líneas además de las líneas telegráficas y telefónicas; y en un plazo de tres años había que avisar si se haría uso del derecho para construir las líneas 3 y 4 . Los reconocimientos (planos y aprobaciones) se harían por tramos de 25 kilómetros y el gobierno pagaría un subsidio de ocho mil dólares por kilómetro construido, que sería percibido en bonos amortizables diez años después de la fecha de cada emisión anual, más el $6 \%$ de rédito. ${ }^{4}$

Hüller y socios eran conscientes de lo que significaba un ferrocarril para su ambicioso proyecto de desarrollo. La visión prevaleciente en aquel momento era la del ferrocarril como precursor del desarrollo y, de hecho, el ejemplo lo tenían allí en las narices ya que en el sur de California se vivían tiempos de masiva inmigración. Aunque el flujo hacia esta región ya era fuerte desde los años cincuenta, con el descubrimiento de oro en Coloma, el movimiento se intensificó con la llegada de las líneas ferroviarias de la Southern Pacific y, poco después, de la compañía ferrocarrilera Atchison, Topeka y Sante Fe, a Los Ángeles, con ramal a San Diego. Solamente entre 1885 y 1886, la población del condado de San Diego creció de 19,500 a 35 mil habitantes (Dumke, 1944:278). ${ }^{5}$

A principios de los años ochenta, la región conocida todavía como Partido Norte de Baja California, prácticamente despoblada, se contaba entre los rincones más alejados y más incomunicados de la república. Para llegar

\footnotetext{
${ }^{4}$ Decreto del Congreso que aprueba el contrato celebrado entre el Secretario de Fomento y Luis Hüller para la construcción de unas líneas de ferrocarril en Baja California, 25 de mayo de 1887, en Archivo General de la Nación, fondo Dublán y Lozano (en adelante AGN, DL), vol. 18 (IIH-UABC, 3.21). El contrato se firmó poco después de que el gobierno federal pasara por un periodo de graves desequilibrios financieros debido al pago de subsidios ferrocarrileros, lo que se podría tomar como una indicación de la importancia que se le daba en aquel momento al desarrollo de la península si no fuera por el hecho de que el gobierno siguió autorizando nuevas concesiones sin mucho criterio, hasta 1899 (Riguzzi, 1996:73-74). Con la estipulación de que la subvención sería pagada en bonos de la deuda pública, el contrato se adelantaba a los criterios que quedarían asentados en la Ley sobre ferrocarriles de 1889 (véase Avilés et al., 1996:137).

${ }^{5}$ Entre 1880-1887, la población de San Diego aumentó en 480\%, la de Los Ángeles en $200 \%$ y la de Santa Bárbara en 285\%.
} 
a Ensenada de Todos Santos, designado puerto de altura y cabecera política en 1882 y elegido como punto neural de las operaciones de la Compañía Internacional, lo más factible era viajar por mar desde Mazatlán (o Guaymas) a San Diego. Desde aquel puerto se tomaba el vapor a Ensenada, un viaje que duraba unas 12 horas en condiciones óptimas o bien, se podía ir por tierra y llegar en cerca de dos días si no había contratiempos. Desde el centro del país, el acceso terrestre a la península estaba bloqueado por el desierto de Sonora y el Río Colorado.

La firme creencia en la riqueza minera de la región era una de las cartas fuertes de la Compañía Internacional de México, pero acceder a los distritos mineros implicaba transitar por brechas -y muchas veces, abrir camino- por territorio a veces muy accidentado, siempre hostil. En resumidas palabras, la empresa empezaba prácticamente desde cero: había que abrir tierras a la agricultura, establecer rutas comerciales con los diversos mercados para dar salida a productos locales, construir caminos para facilitar el acceso a las minas tanto para sacar el material como para meter maquinaria y, sobre todo, atraer inversionistas. Desde la perspectiva de los promotores que deseaban comercializar terrenos, la comunicación y el transporte tenían que ser puntos prioritarios dentro de su programa de desarrollo.

El $1^{\circ}$ de septiembre de 1887 se celebró, con gran alarde, el clavado de la primera estaca del ferrocarril peninsular en la proyectada ciudad de San Carlos (Lower Californian, 1887: 1 de septiembre). ${ }^{6}$ Asistió "todo el pueblo de Ensenada", hubo discursos de Hüller, Sisson y otros directivos de la empresa, así como de Jorge Ryerson, subjefe político, que estaría a cargo del proyecto y que por ello tuvo el honor de colocar la estaca (Lower Californian, 1887: 8 de septiembre). ${ }^{7}$

${ }^{6}$ Ésta se ubicaba a la entrada del valle de El Maneadero, al sur del pueblo de Ensenada. El proyecto de la Compañía Internacional se denominó la colonia Carlos Pacheco, en honor al ministro de Fomento, y consistía de tres ciudades: Ensenada, Punta Banda y la principal, San Carlos.

${ }^{7}$ Poco antes del evento, Hüller había, incluso, pagado a la Tesorería de la Nación el depósito 40 mil dólares en bonos de la deuda pública que garantizaba el cumplimiento del contrato; de hecho, la cantidad depositada cubría la garantía de dos líneas (Comunicación de la Tesorería General de la Federación, 18 de agosto de 1887, en AGN, fondo Secretaría de Comunicaciones y Obras Públicas [en adelante scop], exp. 86/15-1[IHH-UABC, 6.23]). 
El semanario local, Lower Californian, publicado en inglés, informaba debidamente sobre el progreso del proyecto: equipos de ingenieros se encontraban en el campo en búsqueda de la ruta más viable y trazando los planos que tenían que ser sometidos al gobierno para su aprobación. Los reportes eran contradictorios, posiblemente debido a la misma indefinición del proyecto o bien, por querer aplacar intereses encontrados o por la necesidad de ganar tiempo a la vez que mantener viva la promesa de un ferrocarril. En ocasiones se hablaba de la ruta a Yuma, Arizona; en otras se enfatizaba la vía Ensenada-Tijuana. En febrero de 1888, los dirigentes de la Compañía Internacional anunciaron que habían conseguido un préstamo de 600 mil libras esterlinas en bonos ingleses (tres millones de dólares), con lo cual Jorge Ryerson, ahora exsubjefe político, se sintió lo suficientemente confiado como para anunciar que en seis meses estaría en plena función una línea entre Ensenada y San Diego (Lower Californian, 1888: 23 de febrero y 1 de marzo).

Sin embargo, para noviembre Hüller, como representante de la Compañía Ferrocarril Peninsular, constituida expresamente, solicitaba una prórroga de ocho meses para dar principio a los trabajos de construcción; señalaba la falta de mano de obra y el comienzo de la estación de lluvias como principales motivos para el retraso, además de "los muchos y complicados negocios que han ocupado la atención de la Compañía...". 8 Los 'muchos y complicados negocios' se referían a causas de mucho más peso: la Compañía Internacional hacía tiempo para finiquitar el traspaso formal de sus concesiones a otra empresa.

La llegada de miles de inmigrantes al sur de California, todos en búsqueda de un lugar propio para asentarse, había engendrado una especulación intensiva con terrenos, conocida como el boom de los años ochenta aunque no llegó hasta el fin de la década. En la primavera de 1888, se derrumbó de forma repentina el mercado de bienes raíces arrastrando a toda la región a una severa crisis económica (Dumke, 1944:9). El colapso del mercado apuró la crisis interna de la Compañía Internacional. Para principios de 1888 era notorio que la compañía tenía serios problemas, la mayoría de su propia fabricación: deudas, numerosos litigios por cuestio-

${ }^{8}$ Luis Hüller a Carlos Pacheco, secretario de Fomento, noviembre de 1888, en AGN, SCOP, 86/22-1 (IIH-UABC, 7.2). 
nes de duplicidad en la venta de terrenos y títulos no entregados, pleito judicial con su principal agente de bienes raíces, entre otros (Kearney, 1944:80; Heath, 2002:266-272). Con la crisis y la resultante pérdida de confianza, se paralizaron las ventas de terrenos a los dos lados de la frontera y se retiraron tanto inversionistas como colonizadores del norte de Baja California.

La Compañía Internacional se vio orillada a deshacerse de sus múltiples intereses antes de perderlos por completo. Percatada de las corrientes políticas en México, y valiéndose del sentimiento antiestadounidense prevalecente en el país, que veía con temor la presencia de una empresa de tal envergadura justo en el espacio fronterizo, buscó comprador en Europa. De hecho, aprovechó las relaciones ya establecidas con los británicos con los que había concertado el préstamo ferrocarrilero, a sabiendas de que sería tarea menos ardua convencer al gobierno mexicano para que autorizara el traspaso.

Las negociaciones con los ingleses empezaron a mediados del año de 1888; en agosto hubo una serie de entrevistas con el gobierno de Porfirio Díaz; para octubre una nueva mesa directiva con base en Londres entraba en acción con el arribo a Ensenada del mayor Buchanan Scott como el director local (Chaput, 1987:159). ${ }^{9}$ Sin embargo, el traspaso formal se realizó hasta mayo de 1889 , momento en que la nueva empresa, bajo la razón social de Mexican Land and Colonization Company (Compañía Mexicana de Terrenos y Colonización), de capital británico, adquirió todos los bienes de la Compañía Internacional. En el paquete venía incluida la concesión del ferrocarril.

\section{La controversia en torno al proyecto del ferrocarril peninsular}

Cuando la Compañía Internacional obtuvo posesión de una enorme extensión de territorio justo en la frontera con Estados Unidos, despertó inquietud y animosidad entre los políticos mexicanos del interior. Se tra-

\footnotetext{
${ }^{9}$ El mayor Scott, perteneciente al cuerpo de ingenieros de su Majestad Británica, se encontraba comisionado en la India donde supervisaba la construcción de ferrocarriles. A invitación del director, Sir Edward Jenkinson, de la nueva mesa salió de allí con la idea de que venía a Baja California para dirigir la obra del tren peninsular, pero a medio camino se le informó que iba en calidad de director de las operaciones locales.
} 
taba nada menos que de la región más codiciada por los vecinos del norte, desde el momento en que se les escapó de las manos en las negociaciones del Tratado de Guadalupe-Hidalgo. Y aunque la política exterior profesada por el gobierno estadounidense de aquella época no contemplaba más extensión territorial, dentro de la misma sociedad, sobre todo la californiana, había sectores que aún abogaban por la posesión de la península. El nerviosismo en el centro de México era alimentado por la prensa estadounidense, ya que los cónsules mexicanos en San Diego y San Francisco no dejaban de informar al gobierno de todos los acontecimientos y rumores que circulaban por la región.

La Compañía Internacional no podía declarar abiertamente que su objetivo final era tomar el territorio, pero había individuos que no vacilaban en decirlo. Una y otra vez, se recalcaba que la península, en términos geográficos y topográficos, era una extensión del sur de California y la posible existencia de riquezas minerales les confirmaba en la "conclusión lógica" de que la península les pertenecía por derecho (Lower Californian, 1887: 1 de septiembre; León-Portilla, Muriá, 1992:626). Además, razonaban que la línea fronteriza impedía el desbordamiento de población hacia el otro lado de la frontera así como entorpecía la posibilidad de que la región adquiriera la misma prominencia que gozaba su vecino del norte.

Expresiones de tal índole no podían ser menos que alarmantes y las críticas al gobierno de Díaz eran fuertes, al grado de que tuvo que emprender varias medidas, con el doble objetivo de asegurar su control sobre la región y aplacar a sus contrincantes. Entre éstas se encontraban el cambio de categoría del territorio, de Partido a Distrito, para asegurar la comunicación y el control directo por parte del gobierno central (como partido dependía administrativamente de Baja California Sur); el reforzamiento del ejército y el envío del general Luis Emeterio Torres en calidad de jefe político (quien ejercía a la vez como gobernador de Sonora). Torres llegó en enero de 1888 con la encomienda de vigilar de cerca los movimientos de la Compañía Internacional y las actividades de los nuevos colonos inmigrados, así como enviar informes mensuales en los que Díaz le pedía que expresara su propia opinión.

Era inevitable que saliera el tema del ferrocarril. En dos cartas a Díaz, escritas al poco tiempo de haber llegado, Torres manifestaba que "[...] si desde hoy no se pone un cimiento de una inmigración que neutralice 
los intereses norteamericanos, la anexión a los Estados Unidos tiene que venir forzosamente" ${ }^{10}$ Por lo tanto, respecto del proyecto del ferrocarril, sostenía que sería un gravísimo error hacer el entronque con las líneas norteamericanas en Tijuana, antes que con la línea a Sonora, "porque apresuraría la irrupción que tratamos de detener, antes de darnos tiempo para saber como manejarla [...]". ${ }^{11}$

A pesar de la controversia en torno al tema, ${ }^{12}$ tanto partidarios como adversarios de Díaz parecieron coincidir en la necesidad de un ferrocarril en la península, ante el grave problema del extremo aislamiento de la región respecto del resto del país. Asimismo, las dos partes coincidían en insistir en que había que darle prioridad a la línea que ligara a la península con Sonora y no a la que la conectara directamente con Estados Unidos. Pero, las críticas más fuertes apuntaban el nulo avance de la obra.

Una de las medidas conciliatorias emprendidas por el gobierno de Porfirio Díaz fue enviar a Manuel Sánchez Facio, miembro de la oposición, como inspector de colonias. El informe que elaboró Sánchez Facio fue sumamente dañino, sobre todo porque salió publicado justo cuando entraba la nueva mesa británica ${ }^{13}$ y porque no hubo aspecto que no escapara de su escrutinio. Respecto del ferrocarril, de entrada lo calificó de "fantasma" precisamente porque no pasaba de ser un muy mentado y publicitado proyecto. Afirmaba que enlazar Baja California con el interior de la república sería lo más deseable, pero lo consideraba "una utopía irrealizable" ya que se trataba de un camino que tendría que atravesar "tres desiertos, una marisma inmensa y la Sierra Madre [...] Un camino que no es ni de

${ }^{10}$ Luis E. Torres a Porfirio Díaz, 28 de enero de 1888 y 10 de febrero de 1888 . Universidad Iberoamericana, Colección Porfirio Díaz (en adelante UIA, PD) leg. XIII, doc. 001196 (IIH-UABC, 3.25).

${ }^{11}$ L. Torres a P. Díaz, 12 de febrero de 1888. uiA, PD, leg. XIII, doc. 001222 (IIH-UABC, $3.25)$.

${ }^{12}$ A la discusión se incorporaban argumentos que habían sido utilizados respecto de los ferrocarriles en términos generales, sobre todo el peligro a la integridad territorial y más aún, cuando una extensión tan grande de territorio había sido concesionada a una empresa estadounidense. Sin embargo, el gobierno consideraba que el contrato contenía cláusulas que obviaran este problema al quedar sometido al sistema judicial mexicano (véase Riguzzi, 1996:73).

${ }^{13}$ Además, salió publicado en inglés al otro lado de la frontera, contribuyendo enormemente a la desconfianza en los proyectos colonizadores. 
tránsito ni de tráfico" en tanto que se trataba de un territorio totalmente despoblado (Sánchez, 1997:270). ${ }^{14}$ En cambio, la línea Ensenada-Tijuana (San Diego) era factible, pero representaba un enorme peligro si se terminaba antes que la línea 1, pues significaba consumar el estrecho lazo de la vida de la península con la de Estados Unidos y su desarticulación con el resto del país.

A final de cuentas, el conflicto en torno a la construcción del ferrocarril peninsular no era de si se hacía o no -la concesión ya estaba otorgada- sino a qué línea se le daría prioridad; y detrás de este conflicto había diversos intereses en juego que, con la entrada de capitales británicos, iba a adquirir otros matices además de mayor intensidad, ya que el nuevo administrador de la compañía británica, el mayor Buchanan Scott, no dejaba lugar a dudas de que había poco interés en estrechar los vínculos con el mercado estadounidense.

Al tomar posesión, la nueva mesa directiva de la Mexican Land and Colonization Company introdujo cambios importantes en su política y proyecto colonizador. El foco de interés ya no sería la colonia Carlos Pacheco sino San Quintín, a unos 190 kilómetros al sur de Ensenada (aunque Ensenada, por conveniencia o comodidad, seguiría siendo su base de operaciones). Con el fin de lograr el desarrollo de esta región, los nuevos dirigentes en Londres, Sir Edward Jenkinson y Cuthbert Quilter, director y subdirector respectivamente, ambos miembros del parlamento británico, fijaron como prioridades la construcción de un sistema de irrigación en San Quintín y el ferrocarril.

Al mes de llegar a Ensenada, el mayor Scott retomó la exploración del campo, enviando varios equipos a realizar trabajos de reconocimiento con el fin de buscar la ruta más viable. En junio de 1889, la compañía obtuvo una prórroga de dos años seis meses para empezar a construir el ferrocarril ${ }^{15}$ en febrero del año siguiente, solicitaba algunos cambios en las rutas establecidas en la concesión original (véase mapa). El abogado y agente de la empresa en la ciudad de México, Emilio Velasco, explicaba estos cambios:

\footnotetext{
${ }^{14}$ Sánchez Facio (1997:274) señalaba que la línea Central Mexicana, que enlazaba la capital con la frontera y atravesaba varias regiones, había pasado por crisis severas.

${ }^{15}$ Prórroga, junio 1889, AGN, DL, vol. 19, núm. 10,470 (IIH-UABC, 3.34).
} 
[...] las líneas referidas tenían como base que el puerto americano de San Diego sería el centro de negocios de la compañía para la colonización en la Baja California, y en consecuencia se tomaba a Tijuana como el punto de partida para las líneas que debían dirigirse hacia el sur de la Baja California, ya para las que atravesando el territorio debían seguir por Sonora y Chihuahua.

La experiencia ha demostrado que San Diego no era el lugar más adecuado para el centro de estos negocios, mucho menos después que la Compañía se ha reorganizado en Europa, por lo cual el centro de negocios para la colonización no debe buscarse en territorio de los Estados Unidos, sino en territorio mexicano y en la misma Baja California.

En esta virtud se ha escogido a San Quintín como centro para la empresa de la colonización (buscando sólo en el territorio de los Estados Unidos un punto de tránsito para que los colonos procedentes de Europa desembarcando en cualquier puerto americano puedan trasladarse fácilmente a la Baja California, en analogía con estas ideas aconsejadas por el interés de la República, a la vez que por las ideas dominantes actualmente, la Compañía propone algunas modificaciones a los trazos de los ferrocarriles [...] Esas modificaciones sustancialmente se reducen a hacer partir de San Quintín hacia el río Gila la línea que antes salía de Tijuana $[\ldots]^{16}$

Velasco se autocongratulaba por haber inducido a los británicos a "buscar un punto más meridional [...] a fin de que la colonización, en lugar de venir de Estados Unidos hacia California (sic) se extendiera de un punto más céntrico de la California hacia la frontera". ${ }^{17}$ Fuera Velasco el de la iniciativa o no, lo cierto es que trasladar el foco de interés a unos 200 kilómetros al sur (a 300 kilómetros de la frontera) tenía varias ventajas desde la perspectiva de la nueva empresa colonizadora: los terrenos en la región circunvecina a Ensenada se encontraban ya prácticamente todos en manos privadas, mientras que San Quintín contaba con mucho territorio "virgen" $(1,500,000$ hectáreas) para poner a la venta. Por otro lado, es probable que los británicos se percataran de que estaban entrometiéndose en un terre-

\footnotetext{
${ }^{16}$ Emilio Velasco a C. Pacheco, 27 de febrero de 1890, AGN, SCOP exp. 52/8-1 (IIH-UABC, $5.11)$.

${ }^{17}$ Velasco al secretario de Comunicaciones y Obras Públicas, 21 de junio de 1890, en AGN, SCOP, exp. 52/8-1 (IIH-UABC, 5.11).
} 
no económico y estratégicamente importante para Estados Unidos y que, para poder tener un puerto que llegara a competir con el de San Diego, era conveniente poner alguna distancia entre los dos, aun a sabiendas de que la bahía de San Quintín no ofrecía las mismas condiciones adecuadas que la de Ensenada.

\section{Las intrigas de Elisha S. Babcock por el control del comercio del Pacífico}

Poco después de su arribo a Ensenada, Buchanan Scott realizó un viaje a San Diego para efectuar una inspección del sistema de distribución de agua de esa ciudad a petición del empresario Elisha S. Babcock. ${ }^{18}$ No se sabe en qué momento se realizó el primer contacto entre los dos hombres; no se ha encontrado evidencia directa que señale un contacto deliberado, con la intención preconcebida de parte de Babcock de "ganarse la confianza” de la empresa británica.

Elisha Babcock llegó a San Diego en 1884 por razones de salud y en espacio de cuatro años ya había establecido múltiples intereses en el condado: construyó el Hotel Coronado y era dueño de la Coronado Beach Company, de la línea local del tren Coronado y de la San Diego Water Company, que fusionó con la Coronado Water Company; fundó también la Otay Water Company e inició la construcción de dos presas. Se encontraba bien relacionado con John D. Spreckels, capitalista millonario e hijo del magnate azucarero de San Francisco, Claus Spreckels, quien más tarde sería figura clave en la historia empresarial de San Diego y, en particular, de la San Diego \& Arizona Railway Company y de la línea ferroviaria Tijuana y Tecate.

El desplome del mercado de bienes raíces en 1888, mencionado antes, y la resultante depresión representó para Babcock un severo retroceso. Su empresa principal, la Coronado Beach Company, que incluía el Hotel Coronado, perdió 60 mil dólares en dos meses; la compañía de agua, que intentaba vender, se encontraba fuertemente endeudada y sus varios

\footnotetext{
${ }^{18}$ Buchanan Scott a Cuthbert Quilter, 8 de enero de 1890. Buchanan Scott Collection, Special Archives, Guildhall Library, London (en adelante BSC/GL). El informe se encuentra, en hojas sueltas, al principio del letterpress de Buchanan Scott.
} 
proyectos, que incluían una línea ferroviaria entre San Diego y Yuma, peligraban (Tuthill, s.f.:29). ${ }^{19}$ Babcock necesitaba financiamiento de forma urgente.

Poco después de la visita al sistema de agua de San Diego, Babcock le avisó a Scott que planeaba una viaje a Nueva York, por razones que prefería no divulgar, y le pidió una carta de presentación para hablar con "su" gente sobre la cuestión del ferrocarril, ${ }^{20}$ ya que le interesaba la construcción de una línea que conectara a San Diego con Baja California. Es la primera manifestación del interés de Babcock en este asunto. En marzo de 1889, Babcock realizó su primer viaje a Ensenada.

A estas alturas, principios de 1889, recién se había descubierto oro en El Álamo, campo minero localizado a unos 140 kilómetros al sudeste de Ensenada, y para marzo/abril el entusiasmo estaba en su máxima expresión. ${ }^{21}$ Babcock no tenía un interés inmediato en las minas, pero sí procuraba buscar posibles inversionistas, conseguir personal administrativo de confianza, contactar proveedores y aconsejar a Scott respecto de las actividades e inversiones de la compañía. Sobre todo, lo que le interesaba a Babcock de El Álamo era que significaba una garantía de que el ferrocarril se construyera con capital inglés y, tal como a él le interesaba, a San Diego. Pero todavía no jugaba todas sus cartas.

En junio de ese año, Babcock viajó a Nueva York y poco después se hizo público el "asunto secreto" que había querido tratar con los directivos de la empresa colonizadora: la venta de una parte de la San Diego y Coronado Water Works Company a la misma. ${ }^{22}$ Babcock retuvo el $49 \%$ de las

\footnotetext{
19 Tan apretada se encontraba la situación de Babcock, que tuvo que convencer a su esposa que dejara su lujosa casa, recién construida, y se fuera a vivir a unos cuartos, con sus dos pequeños hijos, en el Hotel Coronado.

${ }^{20}$ Elisha Babcock to Buchanan Scott, febrero, 1889. Special Collections, Hotel del Coronado Collection, Malcomb Love Library, San Diego State University (en adelante HCC), Book 5, 247.

${ }^{21}$ A finales de marzo, había unos cinco mil aventureros, la mayoría estadounidenses, muchos de ellos sub o desempleados que sufrían los efectos de la crisis económica. Se organizó un pueblo con 1,677 colonos oficiales, con lo cual rivalizaba en tamaño con Ensenada (Heath, 1999:273,282).

${ }^{22}$ Babcock a W. S. Eaton, Boston, Massachusetts, 23 de julio de 1889, HCc, 6-4. El precio pagado fue de 830 mil dólares; Babcock manifestó querer mantener en confianza el verdadero precio, pero Yaeger (1996) dice que el precio fijado fue de un millón 300
} 
acciones, y la dirección de la compañía de agua fue asignada a Cuthbert Quilter.

Al negociar, o más bien manipular, la venta de la compañía de agua con los ingleses, Babcock dejó estipulado, por un lado, que el sistema de distribución sería arrendado a la ciudad de San Diego a una tarifa que rindiera utilidades atractivas a los ingleses, a cambio de la construcción de una línea ferroviaria entre San Quintín y Tijuana (Yaeger, 1994:83), donde conectaría con el ferrocarril de la Compañía Coronado, para seguir su proyectado camino a Yuma. En pocas palabras, Babcock quería dos cosas: por un lado, que los ingleses construyeran por su cuenta la línea mencionada de San Quintín a Tijuana y no de San Quintín a Yuma, como estaba contemplada; y por otro, que invirtieran en una línea de San Diego a Yuma. La venta de la compañía de agua a los ingleses bajo la promesa de sustanciosas ganancias, además de aportar fondos, era una forma de amarrar a los británicos a este compromiso. A su vez, esperaba utilizar la anticipada inversión inglesa en el ferrocarril para presionar al Consejo de la ciudad de San Diego a que estableciera las cuotas al consumo que él exigía o bien, que tomara el sistema de agua en arrendamiento.

Babcock no quería dejar nada al azar. Poco después de realizado el trato, le comunicó a Scott que John Spreckels, el magnate mencionado anteriormente, había comprado acciones en todas sus empresas, incluso en la compañía de agua, con lo cual se fortalecía enormemente el ambiente de confianza. ${ }^{23}$ También le avisó que había entrado en tratos con varios inversionistas, entre ellos el gobernador de California, para que cedieran parte de sus intereses en terrenos que tenían en el valle de Las Palmas, al sur de la frontera, en beneficio de las vías del ferrocarril. ${ }^{24}$ Esto lo hacía bajo su propia iniciativa y todo mientras insistía sobre la importancia de realizar la obra: "En el momento que haces público el hecho de que la compañía tiene toda la intención de construir el ferrocarril, habrá una precipitación de gente hacia el territorio, como nunca antes". ${ }^{25}$ No sólo eso, insistía en

mil dólares, mientras que Kearney (1944:102) manifiesta que el precio de venta fue de un millón 400 mil dólares. Ninguno de los dos autores cita fuente.

${ }^{23}$ Babcock a Scott, 29 de agosto de 1889, HCC, 6-49.

${ }^{24}$ Babcock a Scott, 2 de octubre de 1889 y 7 de octubre de 1889, HCC, 7-75 y 7-131, respectivamente.

${ }^{25}$ Babcock a Scott, 29 agosto 1889, HCC, 6-49. 
que el proyecto del ferrocarril debería de tomar prioridad sobre el de la irrigación en San Quintín, ya que cada dólar invertido en el ferrocarril le traería a la empresa mayor rendimiento que cada 10 dólares invertidos en la irrigación, por la simple razón de que atraería a la inmigración a "tu país".

De hecho, el interés de Babcock iba mucho más allá de una línea hasta la frontera. Ante la expectativa de la construcción de un canal interoceánico en Centro América, expresó a Spreckels su intención de "controlar la región sur a lo largo de toda la costa de México y América Central y, si fuera necesario, llegar hasta Chile". ${ }^{26}$ Para asegurar este control era imprescindible establecer rutas que conectaran con los mercados del este de Estados Unidos. Quería que Spreckels utilizara su influencia para convencer a la Compañía Ferrocarrilera Atchison y Topeka a que participara en el proyecto de una línea entre San Diego y Yuma, que pasaría por territorio mexicano, asegurándole que la compañía inglesa obtendría los permisos necesarios. A Sir Edward Jenkinson, director de la Compañía Mexicana, le propuso establecer una línea de vapores, en conjunción con la Compañía Atchison, para obtener el control del comercio del litoral del Pacífico para cuando se abriera el canal de Nicaragua. ${ }^{27} \mathrm{Al}$ mismo tiempo, Babcock le escribió una carta a Quilter en la que definió claramente su posición respecto de Baja California: apoyaba de lleno una propuesta del congresista californiano, William Vandever, presentada ante el Congreso de los Estados Unidos en enero de 1889, para la adquisición de la península de Baja California. ${ }^{28}$ Pensaba que la transacción tomaría de dos a tres años, pero él no aflojaría el paso hasta conseguir lo deseado. Le insistía a Quilter sobre la necesidad de empezar de inmediato la construcción del ferrocarril de San Diego a Yuma ya que, una vez iniciada, tendría la cooperación de la Southern Pacific Railway Company y, con eso, lograría su objetivo en poco tiempo. Una vez adquirida la Baja California, aseguraba que las tierras de la compañía valdrían cinco veces más que bajo la bandera mexicana. ${ }^{29}$

\footnotetext{
${ }^{26}$ Babcock a Spreckles, 6 de marzo de 1890, HCC, 9-390.

${ }^{27}$ Babcock a Sir Edward Jenkinson, 21 de enero de 1890, HCC, 8-361.

${ }^{28}$ Aunque el traspaso de la Compañía Internacional a la empresa inglesa no se hizo formal hasta mayo de ese mismo año, es posible que el traspaso de Vandever fuese una medida para desalentar la entrada de los ingleses.

${ }^{29}$ Babcock a Quilter, 21 de enero de 1890, HCC, 8-355.
} 
Las ventajas para Babcock eran evidentes, el porqué se dejaron enmarañar los ingleses lo es menos. En términos generales, estaban ávidos de recuperar la antigua influencia comercial y financiera que habían disfrutado en México y que habían visto menguar a lo largo de 17 años de suspensión de relaciones diplomáticas. ${ }^{30}$ Específicamente, la concesión en Baja California les representaba una oportunidad de abrirse paso en una región clave para Estados Unidos, que era el noroeste de México y el suroeste de California, y hacerse de un puerto estratégicamente ubicado respecto de los circuitos marítimos del comercio del Pacífico. ${ }^{31}$ La compra de la empresa de agua y la inversión en el ferrocarril significaban una ocasión para penetrar y extender su red de relaciones comerciales y financieras (Yaeger, 1994:83).

Sin embargo, para principios de 1890 era claro que no todo marchaba de acuerdo con los planes tan cuidadosamente urdidos por Babcock; la situación con las empresas de agua se complicaba, había intereses rivales con respecto de la vía férrea de San Diego hacia el este y, por último, era obvio que algunos dirigentes de la Compañía Mexicana de Terrenos y Colonización no compartían las ambiciones de Babcock.

En relación con las compañías de agua, había varias que disputaban el contrato de suministro a la ciudad y condado de San Diego ${ }^{32}$ y, de hecho, el pleito entre la empresa de Babcock y la San Diego Flume Company retrasaba la conclusión de la venta a los ingleses. Tan pronto parecía que se había llegado a un arreglo, Babcock se enfrentaba a la hostilidad del Consejo de la Ciudad de San Diego, la Mesa de Consejales y los delegados del comité de agua, que armaban una campaña para reducir las cuotas al consumo de agua a la mitad. Babcock admitió tener más de un enemigo

\footnotetext{
${ }^{30}$ Muchos elementos determinaron la pérdida de posición en el mercado mexicano, pero desde la perspectiva de los mismos comerciantes ingleses, la ausencia de un agente diplomático fue clave. Las relaciones diplomáticas fueron reestablecidas en 1884 .

${ }^{31}$ Unos 50 años atrás se señaló la importancia para los ingleses de tener un puerto en estas latitudes en la primera historia de las Californias en inglés, escrita por Alexander Forbes, quien incluyó en la publicación de su obra varios extractos de cartas escritas por navegadores, así como un mapa. A partir de esta publicación, tener un puerto en costas del Pacífico se convirtió en tema de debate público (Forbes, 1937: 202-220).

${ }^{32}$ De hecho, la San Diego Flume Company suministraba el agua pero la compañía de Babcock se encargaba de la distribución.
} 
en varias agrupaciones. ${ }^{33}$ El disgusto de Babcock ante esta situación -y por el trato "indignante y poco político" otorgado a sus socios, los financieros ingleses- lo llevó a renunciar a su membresía al Comité para fondos para la extensión del ferrocarril y a cancelar su aportación de 60 mil dólares a los fondos subsidiarios del mismo. ${ }^{34}$

Por otro lado, todavía no estaba amarrada la compañía de la Southern Pacific respecto de la línea San Diego-Yuma. Babcock esperaba que la disposición de los ingleses a invertir en esta vía sirviera de gancho para negociar con la Southern Pacific. Vio con cierto optimismo el anuncio de la intención de la Union Pacific Railway Company de entrar al sur de California como una medida adicional de presión. Sin embargo, perdía la paciencia ante lo que él veía como lentitud de los ingleses -poco dispuestos a tomar una decisión hasta no ver cómo se solucionaba el pleito del agua- y en varias ocasiones instó a los dirigentes de la Compañía Mexicana a "tomar la iniciativa”, es decir, iniciar la construcción de la vía férrea para que fuera más fácil convencer a la Southern Pacific sobre la seriedad de los ingleses. En marzo de 1890, Babcock le comunicó a Quilter una nueva preocupación: había tenido una entrevista con uno de los directivos de la Southern Pacific, quien le informó que su empresa tenía más interés en el ferrocarril San Diego-Cuyamaca-Eastern por ser una ruta con mayores posibilidades comerciales. Babcock le hizo varias ofertas y consiguió arreglar una reunión entre J. D. Spreckels y dirigentes del más alto nivel de la Southern Pacific.

Babcock terminó por darse cuenta que él y Scott no compartían objetivos y que el administrador británico y los dirigentes de la Compañía Mexicana no eran tan maleables como él lo hubiera deseado. En la correspondencia entre Babcock y Scott no hay indicación de desacuerdos

\footnotetext{
${ }^{33}$ Véase Babcock al honorable John D. Works, 4 de enero de 1890, HCC 8-288; Babcock a Quilter, 11 de marzo de 1890, HCC 9-234. Es posible que la participación inglesa no haya sido de mayor importancia, pero no deja de ser llamativo el hecho de que muchos historiadores estadounidenses lo ignoran o bien, optan pasar por alto el hecho. Por ejemplo, Hennessey (1978) afirma que cuando, a consecuencia del colapso del mercado de bienes raíces en los años ochenta, peligraban numerosos negocios, Babcock convenció a Spreckels a que invirtiera en sus empresas. Nunca menciona la participación inglesa.

${ }^{34}$ Babcock al honorable Douglass Gunn, Chairman of the Railroad Extension Committee, 27 de febrero de 1890, HCC 9-315.
} 
o asperezas, pero mientras Babcock buscaba cómo asegurarse el control de la península o al menos de su comercio, Scott no perdía oportunidad de exhortar a los colonos a buscar opciones al mercado estadounidense: "Me niego a permitir la importación de cualquier cosa que los colonos puedan producir localmente. Hemos formado una Cámara de Comercio y estamos preparados para ser independientes de Estados Unidos en la mayoría de cosas [...]". ${ }^{35}$ Estaba convencido de que podían controlar el comercio mexicano del litoral pacífico ya que tanto la tarifa proteccionista como las concesiones tan liberales otorgadas por el gobierno mexicano les favorecían. Por otro lado, abogaba por cerrar las oficinas de la compañía ubicadas al otro lado de la frontera (quedó únicamente una en Nueva York) y despidió empleados y abogados estadounidenses. Tampoco había concordancia en cuanto a la estrategia a seguir: Babcock insistía en que se hicieran públicas las intenciones de empezar próximamente la construcción del ferrocarril para empezar a vender terrenos, mientras que Scott quería mantenerlas calladas temiendo precisamente la llegada de capitalistas estadounidenses que especularan con los terrenos. ${ }^{36}$

$\mathrm{Al}$ cabo de año y medio al servicio de la compañía colonizadora, Scott mostró su disponibilidad a solicitar una extensión a su licencia de ausencia de servicio en la India; pero después de una carta de Sir Edward Jenkinson en la que manifiesta que las dificultades financieras de la empresa continuaban, Scott le escribió que sería poco prudente de su parte "perder una buena oportunidad en la India por algo tan inseguro como el proyecto en Baja California”. ${ }^{37}$ El día 10 de mayo, Scott abandonó Ensenada. El 21 de mayo, el San Diego Union y el San Francisco Chronicle desenmascararon un proyecto filibustero fraguado para anexionar Baja California a Estados Unidos. Los instigadores principales eran estadounidenses pero, según iban divulgando los periódicos, eran apoyados por la mesa directiva inglesa y, en particular, por Scott. Ante el alboroto, el gobierno estadounidense se vio forzado a enviar un agente del Departamento de Justicia para

\footnotetext{
${ }^{35}$ Buchanan Scott, fecha y destinatario ilegible, BSC, GL.

${ }^{36}$ Scott a C. Quilter, 8 de enero de 1890, BSC, GL: “...hay decenas de yankis que comprarían terrenos por donde pasaría la vía y te harían pagar mucho por el derecho de paso".

${ }^{37}$ Scott a Jenkinson, 25 de febrero de 1890, BSC, GL.
} 
realizar las investigaciones pertinentes. El informe, en el que se confirmaba la existencia de la conspiración, fue enviado al ministro de la Legación mexicana en Washington, Matías Romero, pero al solicitar las pruebas correspondientes, éstas le fueron negadas por ser "confidenciales". Matías Romero concluyó que "todas son suposiciones, conjeturas o inferencias" y que no había pruebas concluyentes que apuntaran a la culpabilidad de Scott y/o de la Compañía Mexicana. ${ }^{38}$ Después de la declaración de Matías Romero, se calló el asunto en la prensa mexicana y en la prensa estadounidense, se suprimió al adquirir John D. Spreckels el San Diego Union (Yaeger, 1996:79).

Varios investigadores de la historia de la región han abordado el tema, con conclusiones muy encontradas. Kearney (1944:102), en su tesis sobre la empresa colonizadora estadounidense, manifiesta que la "historia del ferrocarril fue una de duplicidad de los accionistas (dirigentes) de las dos empresas, Desarrollo de Baja California (subsidiaria de la Compañía Mexicana de Terrenos y encargada del proyecto de San Quintín) y San Diego Water Company", pero no establece un vínculo con el intento filibustero y Babcock nunca entra dentro del cuadro. Chamberlain (1949:145-155), en su tesis sobre los intereses estadounidenses en Baja California, escrita en 1949 con menos información a su disposición, opinó que la participación de los ingleses era poco probable en vista de la doctrina Monroe y en tanto que eran demasiados los intereses que se jugaban. J. Kirchner (1988) hace hincapié en el papel que desempeñó Babcock por su interés en ver construido el ferrocarril, pero nunca habla del asunto filibustero y apenas menciona la salida de Scott, posiblemente por ser su enfoque el ferrocarril y no la compañía colonizadora. D. Chaput (1987:109), en cambio, “como otros historiadores que han considerado el filibustero (sic), concuerdan que el cuerpo administrativo de la Compañía, particularmente Scott, estaba involucrado en la conspiración”, aunque reconoce lo absurdo de muchas de las conjeturas y alegadas acciones que tramaban los filibusteros. En su trabajo discute poco la relación entre Babcock y Scott. La tesis de J. Yaeger (1994:75) contiene una discusión mucho más completa del mo-

\footnotetext{
${ }^{38}$ Correspondencia de Matías Romero con Manuel Azpiroz, Oficial Mayor de la Secretaría de Relaciones Exteriores y James Blaine, del Departamento de Estado del gobierno de los Estados Unidos, cartas 23 de junio de 1890, 1 de julio de 1890 y 17 de julio de 1890, notas 884 y 937, FIL-I-(IV) (en León-Portilla, Muría, 1992:582-84).
} 
vimiento filibustero, así como del papel de Babcock en relación con las compañías colonizadoras y su interés en el ferrocarril peninsular pero, discípulo de Chaput, no duda de la complicidad de Scott. Más bien, para él es obvia la buena relación entre los dos hombres; comenta, entre otras cosas, que Scott encontró en Babcock un "confidente" con quien compartir su pasión por el ferrocarril.

Pero quizá lo más interesante no es tanto la cuestión de la culpabilidad de Scott, sino más bien la participación y posible complicidad de Babcock. Ciertamente, no hay un documento probatorio y nunca sale a relucir su nombre en todas las noticias que salieron en los periódicos, en las entrevistas y en las averiguaciones. Lo más cercano es una referencia a "una figura millonaria" de San Diego que "se dice" apoyaba al movimiento, así como el hecho de que varias de las reuniones de los conspiradores se llevaron a cabo en el Hotel Coronado. A final de cuentas, y como señala Chamberlain, un movimiento filibustero fraguado por los ingleses, además de improbable, tenía pocas posibilidades de éxito sin importar cuál fuera su objetivo final -crear una nación independiente o un protectorado-, ya que significaba enfrentarse directamente a los intereses estadounidenses y a la doctrina Monroe. Arriesgar una guerra para luego vender o entregar la península a Estados Unidos, no les aportaba ninguna ganancia y sí implicaba arriesgar los demás intereses que tenía esta empresa en Chiapas, Chihuahua, Guerrero y Sonora.

La conclusión más verosímil parece ser la de Chamberlain, al escribir que el movimiento fue inventado para crearle problemas a la compañía colonizadora inglesa. Ciertamente, así lo vio Jenkinson. Su disgusto ante las acusaciones levantadas llegó a tal grado que, en la misma carta a Porfirio Díaz en que profesaba su inocencia, la de la compañía y la de Scott, escribió:

[...] sería de gran beneficio para el país si podíamos establecer comunicación por ferrocarril con el este de México y otras partes, evitando de esta manera que San Diego sea la puerta por decirlo así, por donde se entra a la península. La gente de San Diego hace todo lo que puede por perjudicarnos y de impedir que los colonos pasen a establecerse en nuestros terrenos. ${ }^{39}$

\footnotetext{
${ }^{39}$ Sir Edward Jenkinson a Porfirio Díaz, 11 de junio de 1890, UIA, PD, 5.24. Se refiere a "sus enemigos de San Diego... que actúan de mala fe" y reitera sus intenciones de
} 
El hecho de resaltar la urgencia de establecer comunicación con México sugiere que Jenkinson, al menos, deseaba cortar vínculos con Babcock y sus proyectos. Paralelamente a los sucesos anteriores, Jenkinson, a través de su agente en México, E. Velasco, renegociaba la concesión del ferrocarril sobre todo en términos de las rutas a seguir. Según parece, por referencia que hace Velasco a una comunicación, en un primer momento el gobierno se había negado a autorizar la alteración de los trazos. Pero después del tumulto levantado por el movimiento filibustero y posiblemente convencido por la insistencia y los argumentos de Jenkinson, el 8 de junio de 1890 se publicó un decreto en que se modificaban varios artículos del contrato original, condicionado a que la empresa se obligaba a construir primero la línea que se uniera con el Ferrocarril Central. Las líneas establecidas quedaron como sigue: 1) de San Quintín, pasando por el valle de Trinidad, hasta algún punto sobre el Río Colorado con un ramal desde Trinidad en dirección a Yuma; 2) de esta misma línea, pasando por Trinidad a Tijuana, con ramal a Ensenada de Todos Santos y otro, de San Quintín a la Bahía de los Ángeles; 3) desde el punto en el Río Colorado hasta Magdalena para entroncar con el ferrocarril de Sonora, pasando por Altar con ramal a Puerto Isabel; 4) desde Magdalena hasta ciudad Juárez para entroncar con el Ferrocarril Central Mexicano (véase figura 1). ${ }^{40}$

Aparte de la renegociación del contrato ferroviario, en los siguientes meses se hicieron efectivos varios puntos de la reestructuración de la empresa, que significaba sobre todo crear varias compañías subsidiarias con el fin de aumentar capitales suscritos y la viabilidad de realizar los proyectos. En septiembre, se organizó la Lower California Development Company, o Compañía de Desarrollo de Baja California, para encargarse del desarro-

\footnotetext{
"obrar con lealtad" y en "conformidad con las leyes de la república mexicana y de acuerdo con la política y deseos de V.E.".

${ }^{40}$ Contrato entre C. Pacheco y E.Velasco... reformando algunos artículos de la concesión del 25 de mayo de 1887, 8 de junio de 1890, AGNM, SCOP, exp. 52/8-1 (IIH-UABC, 5.11). En octubre de 1891, las líneas 1 y 2 fueron traspasadas formalmente a la Compañía Ferrocarrilera Peninsular y en diciembre las líneas 3 y 4 fueron traspasadas a Telésforo García bajo la condición de que los dos concesionarios fueran solidarios en el cumplimiento de sus obligaciones, es decir, que los kilómetros construidos por uno contaran a favor del otro. Contratos 27 de octubre y 3 de diciembre, 1891, en AGNM, SCOP, exp. 86/20-1 (IIH-UABC, 6.27).
} 
llo de San Quintín. Ésta le compró a la Compañía Mexicana unos 894 mil acres de terreno en San Quintín, que incluía a la bahía, todos los edificios e instalaciones construidos por la empresa colonizadora (muelle, almacén, hotel), más sus dos vapores. La Compañía de Desarrollo, por su parte, formó la subsidiaria Peninsular Railway Company. ${ }^{41}$ Sin embargo, en tanto que la construcción del primer tramo de la vía ferroviaria empezaría en San Quintín, propiedad de la Compañía de Desarrollo, ésta se encargaría del mismo. Y para esto, Randall H. Pye, uno de los propietarios, declaró tener una compañía organizada en Inglaterra con un capital suscrito de cinco millones 750 mil dólares y un contrato para la construcción con el ingeniero estadounidense R. H. Graham. Se estipulaba que al terminar la construcción del primer tramo, el ferrocarril pasaría al control de la Compañía Ferroviaria Peninsular.

Es probable que Babcock encontraba conveniente mantener un bajo perfil durante estos meses, pero no se había retirado del cuadro. De hecho, no se sabe si fuera consciente o no de las declaraciones de Jenkinson o de los términos de la renegociación del contrato ferroviario, pero no demoró en entrar en contacto con los dirigentes de la Compañía de Desarrollo, C. Hamilton (presidente), R. Pye, F. A. Holdsworth y John Drought. Su correspondencia deja entrever su complacencia ante los cambios, escribió a Spreckels que Pye era maleable, totalmente dispuesto a dejar todos los arreglos necesarios para las obras ferroviarias en sus manos, desde la compra de material (aunque la primera parte se compró en Inglaterra) hasta contratar el ingeniero de obras, R. H. Graham. ${ }^{42}$ En otra carta reveladora, Babcock escribió a "mi querido gobernador": "Me he ocupado con meter en su cabeza [Pye] la necesidad de un camino de San Diego a San Quintín, más que el de San Diego-Yuma [...]”. Menciona que en el transcurso de varias conversaciones se tocó el tema del Valle de las Palmas y habían discutido la posición adversa de Scott, Jenkinson

\footnotetext{
${ }^{41}$ Según Yaeger (1994:61), la compañía peninsular formó otra subsidiaria para comprar la San Diego Water Company. Sin embargo, ya desde junio de 1889, el San Diego Union comenta que Quilter preside la compañía subsidiara, propietaria de la San Diego y Coronado Water Company. El propio Yaeger (1994:77) anota que "una subsidiaria de la compañía colonizadora" negociaba la compra de la Compañía de Agua de San Diego en junio de 1889.

${ }^{42}$ Babcock a Spreckels, 17 de noviembre de 1890, HCC, 15-198.
} 
y Quilter. Termina por comentar: "Pye, siendo comerciante desde hace 24 años, no comparte sus prejuicios y [...] creo que si los puedo inducir a construir hacia San Diego, llegarán a un acuerdo contigo para cruzar el Valle de las Palmas [...] encontré que con el capitán Scott era inútil decir ya cualquier cosa $[\ldots] " .{ }^{43}$

Convencido de que tenía amarrados a los nuevos dirigentes locales, Babcock se dio a la tarea de persuadir a Quilter, a quien no se podía saltar como director de la San Diego Water Company y miembro de la mesa directiva de la Compañía Mexicana, de lo difícil, costoso e inútil que resultaría construir un ramal que pasara por el puerto de Ensenada, al que no le veía ningún futuro comercial. ${ }^{44}$ En resumidas cuentas, la ruta que le interesaba salía por el cañón de Tijuana, pasaba por los valles de las Palmas, Vallecitos, San Rafael y La Trinidad (pasando por el pueblo minero de El Álamo), hasta llegar a San Quintín. En carta a Quilter, además de describir la ruta más viable a su entender, subrayó la importancia del ferrocarril a San Quintín como la opción más barata para la distribución de mercancías en varios puntos del interior, sobre todo en vista de que la mayor parte de las provisiones tendrían que llegar desde San Diego por esta vía, debido al poco calado de la bahía. También destacó las posibilidades de desarrollo que tendría el mineral de El Álamo con el paso de un ferrocarril. Por último, recomendó la colonización con estadounidenses para mejorar el valor de las tierras de la compañía, así como empezar simultáneamente la construcción en los dos extremos de la ruta, Tijuana y San Quintín. ${ }^{45}$

\footnotetext{
${ }^{43}$ Babcock a "My dear Governor", 28 de noviembre de 1890, HCC 15-323. Babcock ya había negociado previamente con el gobernador, la venta de su terreno en Valle de las Palmas a la Lower California Development Company (prometiendo conseguir que lo pagaran a cinco mil dólares) con la finalidad de que la empresa tuviera bienes raíces en esta parte del Distrito Norte y, por lo tanto, mayor interés en construir la línea en dirección hacia San Diego, pues de otra forma no tenía propiedades más al norte de Colnett (80 kilómetros al norte de San Quintín).

${ }^{44}$ Babcock a Quilter, 3 de diciembre de 1890, HCC 15-342. Es probable que el desinterés de Babcock en el puerto de Ensenada tenga sus bases en el hecho de que se encontraba demasiado cercano a San Diego, al igual que los ingleses, aunque por diferentes motivos.

${ }^{45}$ Babcock a Quilter, 28 de noviembre y 3 de diciembre de 1890, HCC 15-316 y 345, respectivamente.
} 
Sin embargo, todavía faltaba por reconciliar los intereses británicos con los de la ciudad de San Diego ya que, mientras persistiera este problema, Quilter y la empresa que representaba no estaban dispuestos a construir hacia San Diego, "amargados" por lo que consideraban una "persecución ultrajante de parte del Consejo citadino". Quilter expresó su convicción a Babcock de que la ciudad de San Diego se había esperado hasta que invirtieran los ingleses, con toda intención de luego acosarlos respecto de las cuotas. ${ }^{46}$

En febrero de 1891, Babcock y Pye se reunieron en el Hotel Coronado con un grupo de influyentes de San Diego con el objetivo de proponer un acuerdo. Pye habló de los adelantos: la formación de una empresa en Londres con el capital ya suscrito y la contratación de una compañía para la construcción de las primeras 45 millas de San Quintín a Yuma. Les informó que los accionistas londinenses podrían ser convencidos de la necesidad de hacer la terminal en San Diego -en cuyo caso la construcción empezaría desde Tijuana- siempre y cuando se llegara a un acuerdo respecto del conflicto entre la empresa de agua y la ciudad de San Diego. La propuesta era la siguiente: que la ciudad de San Diego arrendara la empresa, bajo la garantía de que se pagara el consumo de tres millones de galones de agua por día. El costo del arrendamiento sería de 110 mil dólares anuales, pagables por mes, y el contrato sería por 20 años. Se incluiría una cláusula en la que el síndico inglés, dueño de la concesión ferrocarrilera, se comprometía a empezar la construcción ese mismo año (San Diego Union, 1891: 21 de febrero). ${ }^{47}$

${ }^{46}$ Babcock a J.W. Collins, 4 de diciembre de 1890, HCC 15-405. Según Babcock, el enfado de los ingleses había llegado a tal grado que empezaron a comprar sus provisiones directamente a San Francisco, vía el vapor Newbern, en vez de utilizar sus propios vapores que hacían el recorrido a San Diego. Sin embargo, habría que anotar que, durante estos primeros años, una buena parte del comercio, sobre todo en lo que se refiere a maquinaria para el campo y las minas, se realizaba de por sí con San Francisco debido, entre otras razones, a que los elevados impuestos o tarifas portuarias que se cobraban a los barcos mexicanos en San Diego no se recompensaban con el valor del comercio.

${ }^{47}$ Poco después, el Lower Californian informaba sobre una carta que recibió Babcock de Pye, en que se reitera que la construcción del ferrocarril podría empezar desde Tijuana para el 1 de julio -todavía estaban a tiempo- si se aceptaban las "sugerencias" de la compañía inglesa. 
A mediados de mayo el ingeniero Graham sometió los planos para el primer tramo de 25 kilómetros al gobierno de Díaz. A principios de junio, el San Diegan publicó un telegrama de Babcock en que anunciaba: "He tenido éxito. Graham hizo contrato. Levantamiento línea San Diego a San Quintín. Construcción empieza en Tía Juana tan pronto gobierno autoriza planos". También afirma que Pye fue electo presidente de la Compañía Mexicana, dando a entender que Jenkinson, el principal obstáculo al proyecto, había sido removido de su cargo (Lower Californian, 1891: 11 de junio). Esta afirmación parece ser una mentira deliberada de Babcock, pues Jenkinson seguía ocupando el cargo de presidente. En ningún momento se hace mención -ni por parte de Babcock ni por parte de Pye- del decreto de junio de 1890 en que se modificaron las rutas, ni del compromiso de Jenkinson ante el gobierno mexicano de construir primero la línea que uniera a la península con el resto de México. Es poco probable que los ignorara, sólo resta por pensar que no les daba importancia o, posiblemente, pensaba que las nuevas compañías no estarían atadas a ese compromiso y que, a fin de cuentas, mandaba el capital.

\section{En diez meses, 27 kilómetros}

En julio de 1891 empezó la obra. Poco más de 175 hombres fueron contratados, 90 de ellos mexicanos que "venían del sur" (entre los cuales se contaban indígenas yaquis) y los demás extranjeros, incluyendo a chinos (Lower Californian, 1891: 17 de julio). A la semana se anunciaba la llegada del vapor Fulwell a Ensenada con una locomotora, diez vagones plataforma y 1,800 toneladas de rieles de acero (Lower Californian, 1891: 24 de julio). ${ }^{48}$ Llegó a San Quintín pero debido a su calado de poco más de tres metros, no pudo entrar a la bahía y su carga tuvo que ser llevada en barcazas hasta el muelle, operación que duró más de una semana. Como un presagio, el periódico publicó -y desmintió poco despúes- el rumor de que el muelle de San Quintín se había desplomado, con lo que la locomotora y otro ma-

\footnotetext{
${ }^{48}$ La locomotora era de vapor, pesaba 17 toneladas y fue manufacturada por Manning, Wardle and Company, de Leeds, Inglaterra. Según Yaeger (1994:106), eran dos locomotoras, pero no se ha encontrado otra referencia a una segunda locomotora.
} 
terial pesado se precipitaron al fondo del mar (Lower Californian, 1891: 17 de agosto). ${ }^{49}$

El 13 de mayo de 1892, el mismo periódico anunció que se había parado la obra y que los empleados habían sido despedidos. Habían pasado diez meses en los cuales se construyeron 27 kilómetros; esto significaba dos kilómetros adicionales a los 25 originalmente aprobados, modificación que se solicitó para que el ferrocarril llegara a un punto conveniente para el fondeo y la descarga de buques, y más inmediato al centro poblacional. ${ }^{50}$ Ese mismo mes, Graham viajó a la ciudad de México para someter planos y conseguir la autorización para el siguiente tramo. En julio, el Lower Californian (1892: 8 de julio) reportó que Graham se encontraba camino a Londres con los planos aprobados por el gobierno mexicano.

Las hipótesis esbozadas para explicar la interrupción del proyecto ferroviario han sido numerosas. En una entrevista, Babcock declaró que la empresa colonizadora perdió interés cuando el gobierno mexicano le retiró el permiso de operar la línea (San Diego Union, 1892: 10 de septiembre), declaración que no tiene fundamento. Por otro lado, a Richard Stephens, ingeniero canadiense, no le quedaba la menor duda de que había anomalías y sugería posibilidades de fraude. ${ }^{51}$

Stephens fue contratado originalmente por la Compañía Internacional para realizar un estudio completo del proyecto del ferrocarril. El informe y plano que entregó al mayor Scott fue ignorado completamente. Por diversas maniobras que no se explicaba, que incluía reubicar el centro urbano original de San Quintín a un promontorio que se extendía hasta el centro de la bahía interna, sujeto a inundaciones, el progreso de la obra se retrasó por mucho y se triplicaron los costos. Además, en vez de tomar una ruta directa hacia Colnett, como la que había sugerido Stephens en

\footnotetext{
${ }^{49}$ Por otro lado, el 3 de agosto se anunciaba que habían comenzado las obras (medidas, levantamientos) en San Diego para el ferrocarril a Tijuana; sin embargo, Kirchner (1988:49) anota que no se ha encontrado ninguna evidencia de tales trabajos.

${ }^{50}$ Informe del inspector Juan Valdés, 15 de julio de 1891, AGN, SCOP.

${ }^{51}$ Richard Stephens a "mi muy querida amiga", 1 de agosto de 1892, en Richard Stephens, Records and Letters, Instituto de Investigaciones Históricas, Colección Chaput, exp. 629 (original en Sherman Library, en adelante Rs, SL). El estudio completo, que incluía mediciones, planos y presupuesto, fue entregado por Stephens en 1890 pero se perdió al poco tiempo en un incendio.
} 
el plano entregado, la ruta fue desviada hacia el este, ${ }^{52}$ sobre un camino mucho más complicado y que, además, añadía casi cinco kilómetros más la línea original o, en términos monetarios, al menos otros 45 mil dólares a los gastos. ${ }^{53}$ Sin embargo, es muy probable que la compañía subestimara seriamente los costos de la obra, ya que el escabroso y nada fácil terreno por donde tendría que correr el ferrocarril presentaba grandes desafíos.

Lo cierto es que, no importa desde qué ángulo se analizara la situación, la posibilidad de continuar con la obra ferroviaria se veía cada vez más difícil. En el centro del país, los ferrocarriles y las empresas ferrocarrileras seguían siendo tema de controversia ante la injerencia extranjera y ante los daños al erario nacional por la política de subsidios seguida desde la administración de Juárez (Riguzzi, 1996:74). ${ }^{54}$ Era cada vez más apremiante la necesidad de formular una política coherente que priorizara los requerimientos de transporte y que velara por las necesidades reales del país. Con el fin de recaudar información, la recién creada Secretaría de Comunicaciones y Obras Públicas envió a Juan Valdés como inspector oficial para evaluar la situación de la línea peninsular. Valdés no dudaba de la utilidad de la línea:

[...] se puede asegurar la gran ventaja que ella reportará al país por el mero hecho de poner en contacto este territorio con el resto de la república. Es tam-

\footnotetext{
${ }^{52}$ En una carta de Juan Valdés, inspector oficial, a la Secretaría de Comunicaciones, del 4 de noviembre de 1891, AGNM, SCOP, exp. 86/13-1 (IIH-UABC, 6.21), se explica este cambio en el trazo de la ruta. Para seguir la ruta original había que atravesar una pequeña cordillera que divide a los valles de San Quintín y San Ramón, que significaba pendientes de 3 y 2.5 por ciento y curvas muy pronunciadas, además de que dejaba al rancho de San Ramón a alguna distancia, por lo que se decidió practicar un reconocimiento que flanqueara la cordillera, evitara ascensos y pasara por el rancho, siendo un paso "más ventajoso para el ferrocarril".

${ }^{53}$ Stephens, Rs/sL, exp. 629. Varios años después, en el San Diego Union del 23 de junio de 1898, salió una breve noticia de que J. B. Spreckels y Cía. demandaba a R. A. Graham, conocido contratista, por fraude; el monto involucrado se acercaba al medio millón de dólares.

${ }^{54}$ Todavía faltaba un año para que José Ives Limantour entrara como secretario de la SCOP, pero ya había señalado repetidamente que la misma política de subsidios había llevado a los gobiernos de Brasil y Argentina a la bancarrota y que, para las finanzas de México, también estaba ocasionando un creciente problema.
} 
bién de esperarse que promueva el desarrollo de la agricultura y la minería que comienzan a tener vida [...] y que facilitará el descubrimiento de nuevas fuentes de riqueza en la grande extensión de terreno nunca explorado $[\ldots]^{55}$

Pero en la ciudad de México imperaba más bien el escepticismo. Después de revisar los planos para las dos líneas, presentados por la Compañía de Desarrollo, un administrador de la scop expresó su opinión en el sentido de que era obvio que la Compañía, a pesar de insistir que la principal línea era aquella que se comunicaba con la red mexicana, otorgaba prioridad a la que conectaba con los ferrocarriles estadounidenses, "[...] lo cual sería un mal muy trascendental para México, pues quedaría ese ferrocarril convertido desde luego en americano, y como se encuentra enteramente aislado del resto de las vías férreas mexicanas, la acción del gobierno sobre él sería difícil, tardío y acaso ineficaz". ${ }^{56}$ Aún así, recomendó se aprobaran los planos, con la condición de que se terminara primero la línea que unía el territorio con la red mexicana.

Aun con la recomendación del oficial de la SCOP, no deja de causar cierta admiración el hecho de que el gobierno mexicano haya aprobado los planos para los siguientes tramos del ferrocarril. Entre otras consideraciones, hubo un incidente en el invierno de 1891-1892 que ha sido manejado por los historiadores como un intento de soborno a altos dirigentes del país, nada menos que al mismo Porfirio Díaz, para comprar Baja California. Tal parece que fue una secuencia de malentendidos. Empezó con una conversación que sostuvieron John Drought, uno de los dirigentes de la empresa subsidiaria de San Quintín, y Luis E. Torres, jefe político del Distrito Norte, en noviembre de 1891. Torres le informó a Díaz del diálogo, quien instruyó a Ignacio Mariscal, ministro de Relaciones Exteriores, a que se comunicara con el ministro británico en México, Spenser St. John. Cuando le llegó el informe a Jenkinson en febrero de $1892,{ }^{57}$ era en forma de reclamo y para pedir, en pocas palabras, la cabeza de Drought quien

\footnotetext{
${ }^{55}$ Juan Valdés a scop, 2 de diciembre de 1891, AGN, sCOP, exp. 86/13-1 (IIH-UABC, 6.21).

${ }^{56}$ Ricardo López Guerrero a SCOP, 23 de febrero de 1892, AGN, SCOP, exp. 86/13-1 (IIHUABC, 6.21).

${ }^{57}$ La versión que conocen los historiadores mencionados es el escrito de Spenser St. John en la correspondencia del British Foreign Office.
} 
había ofrecido sumas nada desdeñables tanto a Torres como a Díaz si colaboraban en la venta de la península. ${ }^{58}$

Drought nunca dejó de protestar su inocencia, pero para apaciguar al gobierno mexicano, Jenkinson lo despidió. De hecho, la culpabilidad o inocencia de Drought no le preocupaban mucho. De lo que sí estaba convencido Jenkinson, era que la Compañía de Desarrollo, además de representar una carga desmesurada para la empresa madre (llevaba gastados más de cinco millones de dólares en la Compañía de Desarrollo), le estaba haciendo una guerra desleal al tratar de eliminar a Ensenada como puerto comercial. El historiador Yaeger (1994: 87-90) le da importancia al asunto, sobre todo por el hecho de que Drought, estadounidense según él, era aliado de Babcock y, como él, abiertamente anexionista. ${ }^{59}$

Todavía no se dejaba atrás este asunto, cuando en marzo dos diarios estadounidenses (de Nueva York y Texas) publicaron acusaciones contra Inglaterra por planear apoderarse de la bahía de San Quintín como estación carbonera en anticipación a la construcción del Canal de Panamá. El origen de la acusación fue atribuido a Charles E. Anthony, otro que abogaba por la anexión de la península, quien sostenía que las obras ferroviarias y de irrigación eran para encubrir las acciones de los filibusteros. A este rumor le prestó poca atención el gobierno mexicano, por ser poco coherente en tanto que ya estaba perfectamente informado de lo poco adecuada que resultaba la bahía de San Quintín para tales propósitos (Chaput y Yaeger, 1999:301).

Las condiciones meteorológicas del norte de Baja California durante esos años también tuvieron un papel en el deterioro regional: lluvias torrenciales en el invierno de 1891 con inundaciones en Tijuana, pérdidas agrícolas en Maneadero, San Carlos y San Quintín; seguidas por una sequía a partir del siguiente año que se prolongó por cuatro años y que afectó la actividad económica tanto agrícola como minera y ganadera. Sus-

\footnotetext{
${ }^{58}$ Correspondencia en UIA, PD, leg. XVII. No deja de ser llamativa la carta de Torres a Díaz, 9 de noviembre de 1892, en la que reconoce su torpeza al no percatarse de que Drought quiso "sondearme con proposiciones indebidas" y agradecerle a Díaz su "bondadosa indulgencia".

${ }^{59}$ John Drought era inglés; véase Archivo General de Notarías, Mexicali, libro de protocolización 1892, primer semestre, núm. 2, 4 de enero de 1892.
} 
pendidas las obras del ferrocarril, varios negocios cerraron sus puertas, ranchos se pusieron a la venta y muchos recién inmigrados optaron por retroceder sobre sus pasos. Finalmente, los inversionistas que estaban a la expectativa del ferrocarril acabaron por perder interés.

En el momento que se sometían los planos aprobados a la mesa directiva, había poca duda en la opinión pública de que la construcción seguiría en tanto que la empresa llevaba más de 200 mil dólares invertidos en el proyecto y no iba a renunciar "tan fácilmente" al subsidio de 12 mil pesos por milla construida (Lower Californian, 1892: 11 de marzo). ${ }^{60} \mathrm{El}$ propio Sir Edward Jenkinson, con la seguridad del prestigio que su título de nobleza y su estatus de miembro parlamentario (Spence, 1995:52) ${ }^{61}$ le otorgaba a la empresa, y por haber aceptado presidirla bajo la condición de que se realizaran los proyectos del ferrocarril y la irrigación, expresaba su confianza de que la mesa directiva aceptaría los nuevos planos. Pero no fue el caso, y en septiembre de 1892, Jenkinson y Quilter presentaron sus renuncias (Lower Californian, 1892: 30 de septiembre) ${ }^{62}$

A fin de cuentas, no estaba en manos de la mesa directiva aprobar o no el dinero para seguir adelante con la construcción del ferrocarril. Desde algún tiempo había renuencia de parte de los socios capitalistas a suscribir más capital a un proyecto que no reportaba utilidades y al que no se le veía mucho futuro. Pero, más allá de eso, la crisis financiera de Inglaterra, provocada por la insolvencia de la casa banquera Baring en 1890, frenó severamente el flujo de capital inglés hacia el exterior y la Compañía Mexi-

\footnotetext{
${ }^{60}$ Según Yaeger (1994:86), la empresa tenía que haber completado 32 kilómetros para poder reclamar ese derecho. No cita fuente y no se ha encontrado confirmación del dato.

${ }^{61}$ Era práctica común, como medida promocional, incluir dentro de la mesa directiva de una empresa a personas "respetables", con algún título de nobleza, pero sin ninguna función activa. Tanto Jenkinson como Quilter parecen haber salido del patrón común de figura meramente simbólica al haber participado activamente en los negocios de la compañía.

${ }^{62}$ Sin embargo, ni Jenkinson ni Quilter se retiraron por completo del panorama: Jenkinson aceptó formar parte de un comité mediador entre las dos compañías y el gobierno mexicano (véase E. Velasco a P. Díaz, 20 de noviembre de 1893, UiA, PD, leg. XVIII, doc. 0016309). Todavía en 1894, viaja a la ciudad de México para entrevistarse con Díaz en relación con asuntos de la empresa (véase Velasco a Díaz, 26 de febrero de 1894. UIA, PD, leg. XIX, doc. 002359).
} 
cana de Terrenos y Colonización no fue ninguna excepción. Scott se había quejado en numerosas ocasiones de que la empresa no le daba el efectivo necesario para cubrir ni siquiera los gastos ordinarios. Babcock mismo le informaba a Graham de posibles retrasos en la toma de decisiones debido a que, según le comentaba Pye, los aprietos financieros en Inglaterra eran mucho más severos de lo que se había pensado. ${ }^{63}$

¿Dónde quedó Babcock para todo esto? Después de los dos incidentes 'filibusteros' de principios de 1892, dejó de corresponder con los dirigentes de la Compañía de Desarrollo y desapareció del cuadro bajacaliforniano sin hacer más ruido. Aunque Yaeger $(1994: 90,85)$ parece relacionar el retiro de Babcock con la vergüenza del intento de soborno (con lo que sugiere que podría haber estado conectado) ${ }^{64}$ lo más factible es que Babcock se percató de que la construcción del ferrocaril a San Diego era imposible, debido a las ya irreconciliables diferencias entre la Compañía Mexicana de Terrenos y Colonización y la Compañía de Desarrollo de Baja California, así como el hecho de que la compañía inglesa no tenía ni la intención ni la posibilidad de invertir más dinero en el ferrocarril, dada la recesión banquera mundial. ${ }^{65}$

${ }^{63}$ Babcock a R.A. Graham, 13 de diciembre de 1890, cc 16-49. No se acababan de disipar los efectos de esta crisis cuando en 1892 se cayeron los precios de los metales, en particular de la plata, y vino otra depresión internacional que, de nuevo, afectó momentáneamente los movimientos de capitales (véase Spence, 1996:225).

${ }^{64}$ Yaeger afirma que también se rompió la relación entre el proyecto del ferrocarril y el contrato de agua; desafortunadamente, no se ha podido confirmar la información. Dentro de la historiografía californiana, difícilmente se encuentran referencias a la participación inglesa en la compañía de agua. En el artículo de "Politics of Water", Hennessey (1992) hace referencia a las repetidas confrontaciones entre las dos primeras empresas de agua, San Diego y San Diego Flume, y sin embargo, manifiesta que la primera de éstas ocurrió entre 1896 y 1897. En una entrevista realizada por E. Fletcher a Babcock, en Mandelville Library, Special Collections, mss 81, box 72, file 25, se hace mención de la compra del $51 \%$ de las acciones de la San Diego Water Company por parte de los ingleses y su interés de consolidarse con la Flume Company, de la cual también tenían acciones; Fletcher comenta únicamente que su relación con ellos duró uno o dos años.

${ }^{65}$ A manera de colofón, Babcock siguió padeciendo sus propias dificultades financieras y acabó por vender sus diversos negocios, a lo largo de varios años, a John Spreckels. 


\section{Conclusiones}

Durante los siguientes años, hubo algunos esfuerzos por mantener viva la ilusión de un ferrocarril operacional. Pero para 1898 era más que claro que el ferrocarril no se iba a terminar y la correspondencia entre las oficinas del gobierno federal giraba en torno a qué hacer con la concesión, con la subvención y con los 27 kilómetros del tramo construido, discusión que, a final de cuentas, venía a reflejar los cambios en la política nacional ferroviaria.

No dejan de ser llamativos los términos más bien contradictorios en que se llevaba a cabo la discusión sobre el destino del ferrocarril. Si bien se enfatizaba la inutilidad de la vía construida (¿cómo iban a ser útiles 27 kilómetros de vía que no llegaban a ningún lado?), no se dejaban de reconocer las dificultades que había para trasladarse dentro de Baja California, ni la necesidad de comunicarla con el resto del país. En una época en que el ferrocarril era considerado el gran precursor del progreso, sus ventajas eran obvias: abrir terrenos al cultivo, elevar el valor de los mismos, dar acceso a los recursos naturales, sobre todo los minerales, posibilitar el crecimiento sostenido de la población y acelerar el comercio. En el resto del país se habían construido más de cinco mil kilómetros de vías hasta 1883 , y había sido "extraordinario" su efecto sobre la economía, ya que, entre otras cosas, interconectaban regiones mineras y agrícolas, así como los mercados de las costas y la frontera norte (Haber, 1992:29). En septiembre de 1898, Limantour dio a conocer los nuevos lineamientos que regirían la construcción y el financiamiento de ferrocarriles y puertos, en los que se daba prioridad a aquellas líneas que se consideraba que satisfacían mejor las necesidades del país, entre ellas las que integraban la costa del Pacífico con el centro (Ortiz, 1987:212-213). Sin embargo, Baja California no fue contemplada, a pesar de estar sobre la costa del Pacífico, de ser territorio fronterizo y del hecho de que seguía siendo un territorio despoblado e incomunicado y, por lo tanto, frágil y vulnerable.

La historia del proyecto del ferrocarril peninsular subraya la disyuntiva que se presentaba para la región fronteriza de Baja California en la época del porfiriato: cómo poblar, desarrollar y comunicar a un territorio tan alejado del centro del país cuando no había los recursos ni humanos ni financieros, sin recurrir al capital extranjero; cómo evitar que esta región 
cayera bajo la influencia económica y política de Estados Unidos. Aprobar una concesión a una compañía de capital estadounidense no pareciera ser la solución más adecuada y, como ya se vio, fue muy cuestionada. Por esa misma razón, el gobierno mexicano acogió la oportunidad brindada por los propios estadounidenses: la entrada de un poder europeo que sirviera de baluarte contra la expansión de Estados Unidos. Este capítulo de la historia de Baja California ilustra no sólo una fase de la expansión denominada pacífica de Estados Unidos mediante los proyectos ferroviarios, sino parte de la larga rivalidad entre este país e Inglaterra por la hegemonía económica en México, contienda que ya tenía perdida Inglaterra desde tiempo atrás.

\section{Archivos}

SCOP/AGn Secretaría de Comunicaciones y Obras Públicas/Archivo General de la Nación.

DL/AGN Dublán y Lozano.

PDur Colección Porfirio Díaz, Universidad Iberoamericana. Estos tres fondos fueron consultados en la biblioteca del Instituto de Investigaciones Históricas de la UABC, razón por la cual se incluye la referencia.

BSC/GL Buchanan Scott Collection, Special Archives, Guildhall Library, Londres.

FC/ML Fletcher Collection, Special Collections, Mandelville Library, University of California, San Diego.

hcc/sdsu Hotel del Coronado Collection, Special Collections, Malcolm Love Library, San Diego State University.

\section{Bibliografía}

Avilés Rodríguez, E. et al. (1996), "Notas sobre historia y cultura ferrocarrilera" en Memorias del Tercer Encuentro de Investigadores del Ferrocarril, Puebla, Puebla, SCT, Dirección General de FNM.

Chamberlin, E. K. (1949), "United States Interests in Lower California”, tesis de posgrado, California, University of California.

Chaput, D. L. (1987), "The British are Coming! Or, The Army of India and the Founding of Ensenada”, The Journal of San Diego History, núm. 33, otoño 1987, 151-164.

y J. Yaeger (1999), “Compañía Mexicana de Terrenos y Colonización, 1887-1917”, en Ensenada: nuevas aportaciones para su historia. Mexicali, Baja 
California: Instituto de Investigaciones Históricas, Universidad Autónoma de Baja California.

Dodge, R. V. (1964), "Low Rails in Lower California”, The Dispatcher, Railway Historical Society of San Diego, núm. 48, 31 de diciembre, 1964.

Dumke, G. S. (1944), The Boom of the Eighties in Southern California, San Marino California, Huntington Library (1991, 6a. impresión).

Forbes, A. (1937), California. A History of Upper and Lower California, San Francisco, John Henry Nash (Nueva York: Kraus Reprint Co., 1972).

Haber, S. (1992), Industria y subdesarrollo, La industrialización de México, 1890-1940, México, Alianza ( $1 \stackrel{a}{a}$ ed. en inglés, 1989).

Heath, H. J. (2002), "La época de las grandes concesiones, 1883-1910”, en C. Velázquez (coord.), Baja California: un presente con historia, tomo 1, Mexicali, Baja California, UABC.

(1999), "El poblado minero El Álamo", en M. A. Samaniego (coord), Ensenada: nuevas aportaciones para su historia, Mexicali, Baja California, Instituto de Investigaciones Históricas, Universidad Autónoma de Baja California.

Hennessey, G. (1978), “The Politics of Water in San Diego, 1895-1897”, en The Journal of San Diego History, vol. 24, núm. 3, verano de 1978 (versión electrónica: http://www.san diegohistoryorg/journal/78summer/water.htm).

Holden, R. (1990), "Priorities of the State in the Survey of the Public Land in Mexico, 1876-1911", Hispanic American Historical Review 70, núm. 4, p. 585.

Kearney, R. E. (1944), "American Colonization Ventures in Lower California, 1862-1917", tesis de maestría, California, University of California.

Kirchner, J. A. (1988), Baja California Railways, Los Ángeles, California, Dawson's Bookshop.

León-Portilla, M. y J. M. Muriá (1992), Documentos para el Estudio de California en el siglo XIX, tmo III, México, Futura Editores.

Ortiz Hernán, S. (1987), Los ferrocarriles de México. Una visión social y económica. I. La luz de la locomotora, México, Ferrocarriles Nacionales de México (1르 ed. 1970).

Riguzzi, P. (1996), "Los caminos del atraso: tecnología, instituciones e inversión en los ferrocarriles mexicanos, 1850-1900", en S. Kuntz Ficker y P. Riguzzi (coords.), Ferrocarriles y vida económica en México (1850-1950). Del surgimiento tardío al decaimiento precoz, Zinacantepec, Estado de México, El Colegio Mexiquense, Universidad Metropolitana Xochimilco, Ferrocarriles Nacionales de México.

Sánchez Facio, M. (1997), "Informe relativo a la visita de inspección practicada a las colonias establecidas en el territorio de Baja California (1888)", en C. Pacheco y Sánchez Facio, La controversia acerca de la política de colonización en Baja California, Mexicali, Baja California, SEP/UABC, Colección Baja California: nuestra historia, núm. 12. 
Spence, C. C. (1995), British Investments and the American Mining Frontier, 18601901, Moscow, Idaho, University of Idaho Press.

Tuthill, B. (s.f.), “Elisha S. Babcock: San Diego's Gentleman from Indiana”, mecanoescrito, San Diego History Center, Library and Manuscripts Collection.

Yaeger, J. (1994), "Mexican Land and Colonization Company, 1889-1917. British Venture Beyond the Pale", tesis de maestría, San Diego, California, San Diego State University.

\section{Hemerografía}

Lower Californian, Ensenada, años 1886-1894. San Diego Union

Recibido el 28 de marzo de 2011 Segunda versión recibida el 28 de septiembre de 2011

Aprobado el 28 de octubre de 2011 